\title{
The use of hedgerows as flight paths by moths in intensive farmland landscapes
}

\author{
Emma Coulthard $^{1} \cdot$ Duncan McCollin $^{2} \cdot$ James Littlemore $^{3}$
}

Received: 5 February 2016/Accepted: 11 April 2016/Published online: 23 April 2016

(c) The Author(s) 2016. This article is published with open access at Springerlink.com

\begin{abstract}
Linear boundary features such as hedgerows are important habitats for invertebrates in agricultural landscapes. Such features can provide shelter, larval food plants and nectar resources. UK butterflies are known to rely on such features, however their use by moths is understudied. With moth species suffering from significant declines, research into their ecology is important. This research aimed to determine whether UK moth species are using hedgerows as flight paths in intensive farmland. The directional movements of moths were recorded along hedgerows at 1,5 and $10 \mathrm{~m}$ from the hedgerow face. The majority of moths recorded within the study were observed at $1 \mathrm{~m}$ from the hedgerow ( $68 \%$ ), and of these individuals, $69 \%$ were moving parallel in relation to the hedge. At further distances, the proportion of parallel movements was reduced. These results suggest that hedgerows may be providing sheltered corridors for flying insects in farmland landscapes, as well as likely providing food plants and nectar resources, emphasising the importance of resourcebased approaches to conservation for Lepidoptera.
\end{abstract}

Keywords Hedgerows · Wildlife corridors .

Lepidoptera $\cdot$ Moths $\cdot$ Linear boundary features

Emma Coulthard

e.coulthard@mmu.ac.uk

1 School of Science and Engineering, Manchester Metropolitan University, John Dalton Building, Chester Street, Manchester M15 6BH, UK

2 University of Northampton School of Science and Technology, St Georges Avenue, Northampton NN2 6JD, UK

3 Moulton College, West Street, Moulton, Northampton NN3 7RR, UK

\section{Introduction}

Hedgerows are important habitats for butterflies in UK landscapes and as many as 39 of the UK's 61 (resident or regular migrant visitors) butterfly species are thought to rely on hedgerow habitats to some extent (Lewington 2003; Dover and Sparks 2000). The sheltering effects of hedgerows and other shrubby habitats are known to be important for Lepidoptera (Dover and Sparks 2000; Merckx et al. 2010b). It is probable that some of the thousands of UK resident moth species utilise hedgerows to a similar extent as butterflies, however this is much less researched (Waring et al. 2009; Manley 2008; Butterfly Conservation 2007; Fox et al. 2011; Fox 2013; Kimber 2014). A study into the benefits of woody hedgerows in farmland, found that moth abundance ws higher along hedgerows than in surrounding agricultural fields (Boutin et al. 2011). Merckx et al. (2010b) suggested that one species in particular, the Pale Shining Brown (Polia bombycina), was likely to be following hedgerows, due to its mobility and habitat preferences.

The abundance of flying insects in farmland is known to be positively associated with sheltered linear features such as hedgerows and windbreaks, as such features reduce the influence of wind speed and hence convective cooling on such ectothermic organisms (Bowden and Dean 1977; Lewis 1969, 1970; Lewis and Dibley 1970; Merckx et al. 2008; Passek 1988). Research comparing the abundance of airborne insects along artificial windbreaks showed that higher numbers of individuals accumulated against features of lower permeability (Lewis and Dibley 1970). Similar research on low hedgerows and airborne insects revealed that this accumulation also occurs along hedgerows under windy conditions (Lewis 1969). Where tree windbreaks are concerned, it was found that wind speed was one factor in 
the abundance of insects recorded, however the vegetative composition appeared also to be influential (Lewis 1970). A later study by Bowden and Dean (1977), found that over a long term study, insect abundance along hedgerows was associated with vegetative species richness rather than wind speed or direction. For shrubby linear features, it is likely that the association with flying invertebrates is due to a combination of factors, but it is clear that such features could provide both shelter and vegetative resource benefits to invertebrates.

A study of sheltered green lanes by Dover et al. (2000) found that significantly more butterfly species were recorded within green lanes than outside, and that the species composition was different. The study also highlighted the importance of hedgerows for the movement of butterflies. A later study by Dover and Fry (2001) aimed to simulate the effect of hedgerow resource visibility versus physical barriers on three free-flying butterfly species' movements. The authors simulated physical hedgerow structure with sheeting and the visual stimulus of hedge flowers with red and white tape. The research found that the three species reacted differently to the purely visual stimulus, with the High Brown Fritillary (Fabriciana adippe)/Niobe Fritillary (F. niobe) complex following the tape, the Heath Fritillary (Mellicta athalia) unaffected, but Scarce Copper (Heodes virgaureae) responded to the tape stimulus as a barrier. The physical sheeting 'hedgerow' however acted as a partial barrier and as a corridor to all three species, with most individuals flying along the simulated hedgerow. These results suggest that species respond differently according to behavioural ecology, but that the physical structure of a hedgerow can be a barrier to the movements of some butterfly species, as well as a corridor (Dover and Fry 2001). It is probable that macro-moth species have similar variation in their responses to linear landscape features such as hedgerows and field margins. This research aimed to determine the possible use of hedgerows as corridors by moths in agricultural landscapes, by means of nocturnal observations.

\section{Study site and methods}

\section{Study site}

The Moulton College Estate Farm has only recently been entered into Entry Level Stewardship (2010 [Natural England 2013a]), and although conservation driven management is incorporated, it is a low priority when compared with sites in Higher Level Stewardship (Natural England 2013b). The 600 ha site is composed of a mixed lowland farm with mainly arable areas and is run as both a commercial and teaching estate. Due to the high proportion of arable fields across the estate, many hedgerows are not laid, just flailed, resulting in dereliction. Additionally the Moulton estate is farmed intensively and most field margins are narrow and exhibit signs of chemical enrichment (high coverage of weedy nitrogen loving species; McCollin et al. 2000). Survey points were chosen across the estate, along hedgerows in various conditions from 'gappy' and derelict, to thick and regularly managed. Hedgerows also needed to be readily accessible to researchers carrying equipment. Surveying was not carried out directly adjacent to any hedgerow gaps, due to the possible impact on movement and flight behaviour.

\section{Methods}

A study investigating the movements of bumblebee species in relation to hedgerows used an observational method to categorise bee movements as parallel, right angles, diagonal or irregular in relation to the hedgerow orientation (Cranmer et al. 2012). Such observations were taken along a transect at distances of zero, 10, 20 and $30 \mathrm{~m}$ from the hedgerow face (Cranmer et al. 2012). Their method was adapted for use in investigating moth movements along hedgerows. As with the Cranmer study, points were chosen at different distances from the hedgerow (in this case 1, 5 and $10 \mathrm{~m}$; Fig. 1). For the purposes of this study (due to the sheer volume of moths on some night), the orientation of diagonal and right angled movements were not recorded. Moth behaviour is affected by certain lights, specifically those at the ultraviolet and blue ends of the spectrum, so any use of normal visible light torches might affect the. A red light torch was chosen instead for this study, as it would be less likely to affect behaviour (Gilburt and Anderson 1996; van Langevelde et al. 2011). Observations took place on warm nights (over $5{ }^{\circ} \mathrm{C}$ ), as Lepidoptera activity is known to be significantly affected by adverse weather conditions (Yela and Holyoak 1997). A total of 13 observation sets (observations at each of the three distances) were made over the months of May-July in 2011, 2012 and 2013. Each set of observations was carried out for $45 \mathrm{~min}$, with 15 min spent at each distance. At least two observation sets were carried out on each suitable evening at different hedgerows, between the hours of 23:30 and 02:00 h, weather permitting.

Although many research projects have focused on movements of butterfly species, few studies have looked at moth movements. Mark-Release-Recapture experiments have frequently been used to analyse the dispersal of insects such as butterflies. This method has been adapted for moths, using light traps to capture and recapture moth species and study their dispersal around landscapes (Merckx et al. 2009a; Merckx et al. 2010a; Slade et al. 2013). This method could be used to investigate moth dispersal 
Fig. 1 Numbers of observed moth movements at 1,5 and $10 \mathrm{~m}$ observation points, parallel, diagonal, right-angle or irregular in relation to hedgerow face and percentages for each distance. Results from a total of 13 observation occasions across the study site from the summers of 2010 , 2011, 2012 and 2013

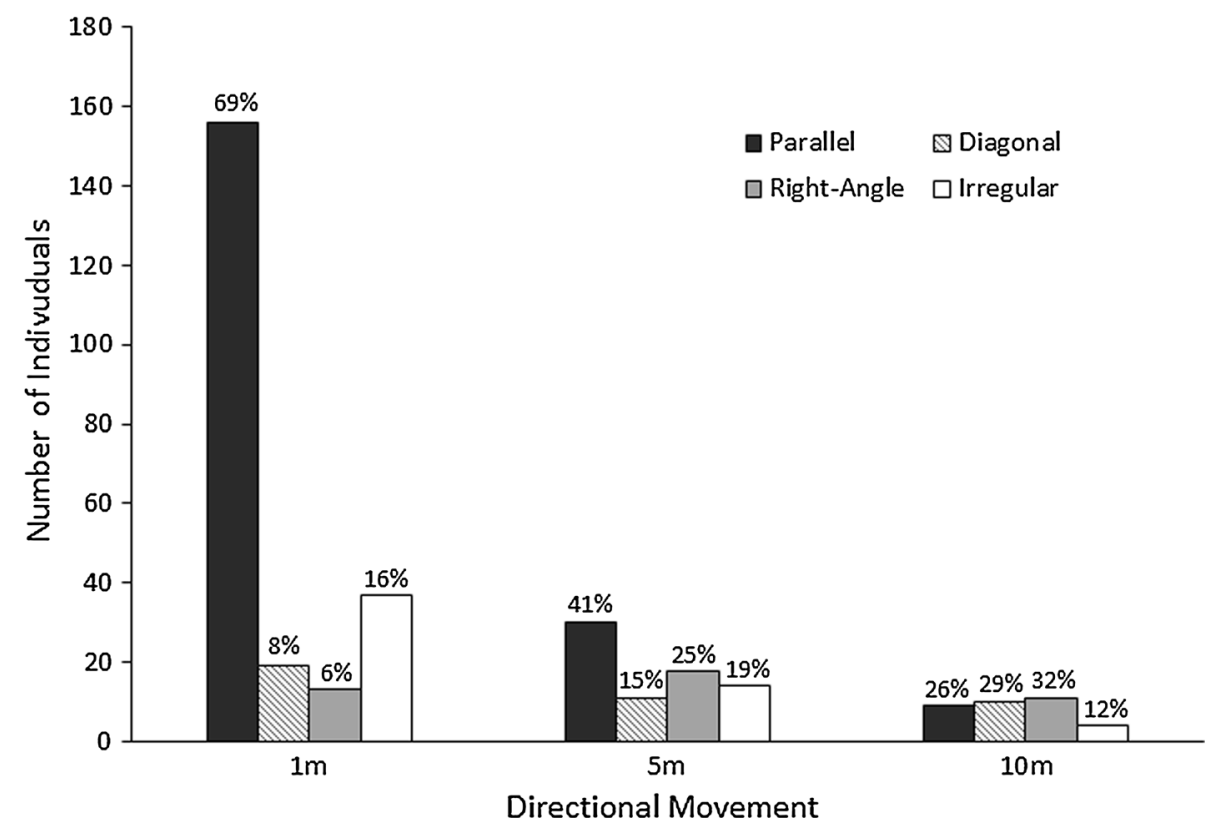

around farm landscapes, however it requires a large amount of human resources and has a low return rate (around $5 \%$ with regards Merckx et al. 2009a; Slade et al. 2013) and was therefore not chosen for this study.

\section{Statistical methods}

The numbers of moths observed at each distance, and each direction were totalled. Analysis of the differences between groups were made using a Kruskal-Wallis test, due to the non-normal distribution of the data, and further pairwise comparisons were carried out between groups. All analysis was carried out in IBM SPSS version 21 (IBM 2011).

\section{Results}

A total of 332 moths were observed in total throughout the study, with moth abundance varying depending on weather conditions. The majority of moths observed were seen at the $1 \mathrm{~m}$ observation point; with $68 \%$ (225) of all moths seen at this distance, $22 \%(73)$ at $5 \mathrm{~m}$ and $10 \%$ (34) at $10 \mathrm{~m}$ (Fig. 1). A Kruskal-Wallis test revealed that the numbers of moths observed at 1,5 and $10 \mathrm{~m}$ were significantly different $(H[3]=34.541, p \leq 0.001)$, with higher numbers of moths observed closer to the hedgerow.

Of the moths seen at $1 \mathrm{~m}$, the majority of moths were observed as moving parallel to the hedgerow face (Fig. 1). The direction of moths at $1 \mathrm{~m}$ from the hedgerow was significantly non-random (Kruskal-Wallis test, $H[3]=17.747, p=0.001)$.
Pairwise comparisons with adjusted $p$-values showed a significant difference between the numbers of moths moving parallel and diagonal at $1 \mathrm{~m}$ from the hedgerow $(p=0.009)$, as well as between parallel and right angle $(p=0.001)$, but not between parallel and irregular $(p=0.068)$.

For moths observed at $5 \mathrm{~m}, 30$ of the 73 moths were seen moving parallel to the hedgerow face $(41 \%)$. There was no significant differences between the directional movements of moths at $5 \mathrm{~m}$ from the hedgerow $(H(3)=1.964, p=0.580)$. At $10 \mathrm{~m}$, only 9 of the 34 moths observed were moving parallel to the hedgerow face (26\%); the results for the $10 \mathrm{~m}$ movement observations were not significant $(H(3)=0.766, p=0.858)$. These results show that at further distances from the hedgerow, moths are moving in a range of directions, rather than just parallel.

\section{Discussion}

\section{Moth abundance and hedgerow proximity}

The majority of moths observed during the course of the study were seen at closer proximity to the hedgerow (68\%). These results suggest that there may be more moth activity along hedgerows than further out along margins and within crop fields. The numbers of moths observed were less at 5 and $10 \mathrm{~m}$ combined than at $1 \mathrm{~m}$ from the hedgerow (Table 1). Indeed, Merckx et al. (2009b), found that abundance of moths was $92 \%$ higher along hedgerow margins than in the centre of fields, with these results being 
Table 1 Observed moth movements at $1 \mathrm{~m}, 5 \mathrm{~m}$ and $10 \mathrm{~m}$ observation points, and respective percentage of overall observations

\begin{tabular}{llllll}
\hline & Parallel & Diagonal & Right-angle & Irregular & Total \\
\hline $1 \mathrm{~m}$ & 156 & 19 & 13 & 37 & 225 \\
$\%$ & $69 \%$ & $8 \%$ & $6 \%$ & $16 \%$ & $68 \%$ \\
$5 \mathrm{~m}$ & 30 & 11 & 18 & 14 & 73 \\
$\%$ & $41 \%$ & $15 \%$ & $25 \%$ & $19 \%$ & $22 \%$ \\
$10 \mathrm{~m}$ & 9 & 10 & 11 & 4 & 34 \\
$\%$ & $26 \%$ & $29 \%$ & $32 \%$ & $12 \%$ & $10 \%$ \\
\hline
\end{tabular}

true for all nine species studied. These figures alone indicate that hedgerows may be key habitat features for macromoths within agricultural landscapes. This result supports the findings from previous studies that hedgerows are important habitat features for invertebrates within agricultural landscapes and more specifically for butterflies and moths (Maudsley 2000; Dover 1990; Merckx et al. 2010b; Slade et al. 2013). Other researchers have found that butterflies may be using hedgerows as wildlife corridors and these results suggest that moths are also using hedges in a similar manner nocturnally (Dover 1990). It is of course unclear whether moths are using the hedgerows as corridors for dispersal, shelter from wind or simply responding to the physical barrier effect of the hedge, as with some butterfly species (Dover and Fry 2001). It is likely that factors such as size, mobility and resource requirements of moth species will have an impact on the behavioural ecology of a species and therefore its response to linear landscape features. Such varied responses have already been observed with moth species to hedgerow trees (Merckx et al. 2010b; Slade et al. 2013).

\section{Moth movement and hedgerow proximity}

The results at $1 \mathrm{~m}$ from the hedgerow showed that most moths within this distance are moving parallel to the hedgerow. The highly significant Kruskal-Wallis results at this distance support the theory that moths may be using hedgerows as flight paths. Moths are likely to be following hedgerows as a visual stimulus, as well as for the possible sheltering effects from wind or rain (Dover and Fry 2001). Due to moth preferences for white flowers as nectar sources, it is possible that flowers along hedgerows and margins could also be acting as a visual stimulus to moths, particularly those which are nectar feeders (Waring et al. 2009; White et al. 1994). There are several influencing factors which make such areas attractive as habitats in their own right, such as nocturnal nectars sources and egg-laying sites (see section: Moth behaviour observations).

The results from the $5 \mathrm{~m}$ observation points showed no significant difference between directional movements at this distance. Although the results were not significant, the highest percentage of moths were still moving parallel to the hedgerow, which suggests that even further out from the hedgerow, some moths may still be using linear boundary features as flight paths, however it is more infrequent at this distance.

The results for $10 \mathrm{~m}$ were also not significant. At this distance the highest percentage (32\%) was for right-angled movements. Movements of moths at this distance may be of moths searching for food sources and egg-laying sites.

The use of hedgerows as flight paths for moths and their predators, such as bats, has implications for their management (Boughey et al. 2011; Entwhistle et al. 2001). In order to maintain the effectiveness of hedgerows as flight paths or 'corridors' they may require planting up where gaps have appeared, to avoid the loss of their functionality. Current management prescriptions under HLS suggest that hedgerow gaps should be filled where possible (Natural England 2013a, b). This finding of this study supports this management policy to some extent, but smaller gaps may provide valuable heterogeneity and allow for low movements across hedgerows. Continuous hedgerow may also create barriers to some populations, so some small gaps should be encouraged, to allow movements. Research into the Brown Hairstreak (Thecla betulae) butterfly, has shown a preference for south-facing, scallop-edged hedgerows for egg laying due to the preferable micro-climates, something which is likely true for other ectothermic insect species (Merckx and Berwaerts 2010), suggesting a need for less 'tidy', flat edged hedgerow.

\section{Moth behaviour observations}

Aside from the moth movement observations, some general notes were taken on moth behaviour along hedgerows. These 'irregular' moths were often moving backwards and forwards, up and down, across the hedgerow face. A number of these moths were seen eventually landing on hedgerow or adjacent margin foliage, possibly in search of egg-laying or feeding sites.

Some brief, observations made of moth behaviour at gaps in the hedgerows suggest that large gaps can have an influence on their value as corridors, as moths were seen travelling through larger gaps (around 20 moths over a $45 \mathrm{~min}$ period), rather than continuing along the hedgerow. Slade et al. (2013) found that a higher number of moths were captures adjacent to hedgerow trees than isolated ones (61 vs $27 \%$ ), suggesting that the presence of trees alone are not influencing moth abundance. As suggested previously, the effect of physical structure is likely different for different moth species, and heterogeneity of hedgerows at a wider scale is important to be sure to provide 
suitable habitats for a wider range of species. Planting of gaps under HLS may disadvantageous for some species, so planting of gaps may be more beneficial for those $1 \mathrm{~m}$ in length or over, allowing for some movements between fields and providing structural diversity.

\section{Summary}

The method used for observing moth movements was inexpensive, easy to carry out and proved successful as an initial way to gauge the use of hedgerows as dispersal routes by moths. The results of the study and related observations suggest that hedgerows and adjacent field margins are important habitat features for moth species in intensive agricultural landscapes with moths seemingly using linear boundary features as sheltered flight paths, feeding sources and egg laying sites. Further research should be conducted to confirm the effects of hedgerow gaps on moth dispersal in these landscapes. Along with unpublished data on moth visitation to hedgerow flowers (Coulthard 2015), this study confirms that hedgerows are important habitat features for moths as well as butterflies, which are already known to depend on hedgerows and other linear features in the UK landscape (Lewington 2003; Dover and Sparks 2000; Dover et al. 2000; Dover and Fry 2001; Ouin and Burel 2002).

Open Access This article is distributed under the terms of the Creative Commons Attribution 4.0 International License (http://crea tivecommons.org/licenses/by/4.0/), which permits unrestricted use, distribution, and reproduction in any medium, provided you give appropriate credit to the original author(s) and the source, provide a link to the Creative Commons license, and indicate if changes were made.

\section{References}

Boughey KL, Lake IR, Haysom KA, Dolman PM (2011) Improving the biodiversity benefits from hedgerows: how physical characteristics and the proximity of foraging habitat affect the use of linear features by bats. Biol Conserv 144:1790-1798

Boutin C, Baril A, McCabe SK, Martin PA, Gui M (2011) The value of woody hedgerows for mot diversity on organic and conventional farms. Environ Entomol 40:560-569

Bowden J, Dean GTW (1977) The distribution of flying insects near a tall hedgerow. J Appl Ecol 14:343-354

Butterfly Conservation (2007) The UK biodiversity action planmoths. Wareham, Butterfly Conservation

Coulthard E (2015) Habitat and landscape-scale effects on the abundance and diversity of macro-moths (Lepidoptera) in intensive farmland. $\mathrm{PhD}$ thesis, University of Northampton

Cranmer L, McCollin D, Ollerton J (2012) Landscape structure influences pollinator movements and directly affects plant reproductive success. Oikos 121:562-568

Dover JW (1990) Butterflies and wildlife corridors. Ann Rev Game Conserv 1989 21:62-64
Dover JW, Fry GLA (2001) Experimental simulation of some visual and physical components of a hedge and the effects on butterfly behaviour in an agricultural landscape. Entemol Exp Appl 100:221-233

Dover JW, Sparks T (2000) A review of the ecology of butterflies in British hedgerows. J Environ Manage 60:51-63

Dover J, Sparks T, Clarke S, Gobbett K, Glossop S (2000) Linear features and butterflies: the importance of green lanes. Agric Ecosyst Environ 80:227-242

Entwhistle AC, Harris S, Hutson AM, Racey PA, Walsh A, Gibson SD, Hepburn I, Johnston J (2001) Habitat management for bats. JNCC, Peterborough

Fox R (2013) The decline of moths in Great Britain: a review of possible causes. Insect Conserv Divers 6:5-19

Fox R, Brereton TM, Asher J, Botham MS, Middlebrook I, Roy DB, Warren MS (2011) The state of the UK's butterflies 2011. Butterfly Conservation and the Centre for Ecology and Hydrology, Wareham

Gilburt H, Anderson M (1996) The spectral efficiency of the eye of Ephestia cautella (Walker) (Lepidoptera: Pyralidae). J Stored Prod Res 32:285-291

IBM (2011) SPSS Statistics version 20. Computer Software, New York

Kimber I (2014) UK Moths: your guide to the moths and butterflies of Great Britain and Ireland. [Online] www.ukmoths.org.uk. Accessed on 08 Sep 2013

Lewington R (2003) A pocket guide to the butterflies of Great Britain and Ireland. British Wildlife Publishing, UK

Lewis $T$ (1969) The distribution of flying insects near a low hedgerow. J Appl Ecol 6:443-452

Lewis T (1970) Patterns of distribution of insects near a windbreak of tall trees. Ann Appl Biol 65:213-220

Lewis T, Dibley GC (1970) Air movement near windbreaks and a hypothesis of the mechanism of the accumulation of airborne insects. Ann Appl Biol 66:477-484

Manley C (2008) British moths and butterflies: a photographic guide. Christopher Helm Publishers Ltd, UK

Maudsley M (2000) A review of the ecology and conservation of hedgerow invertebrates in Britain. J Environ Manag 60:65-79

McCollin D, Moore L, Sparks T (2000) The flora of a cultural landscape; environmental determinants of change revealed using archival sources. Biol Conserv 92:249-263

Merckx T, Berwaerts K (2010) What type of hedgerows do Brown hairstreak Thecla betulae butterfly prefer? Implications for European agricultural landscapes. Insect Conserv Divers 3:194-204

Merckx T, Van Dongen S, Matthysen E, Van Dyck H (2008) Thermal flight budget of a woodland butterfly in woodland versus agricultural landscapes: an experimental assessment. Basic Appl Ecol 9(433):442

Merckx T, Feber RE, Dulieu RL, Townsend MC, Parsons MS, Bourn NAD, Riordan P, Madcdonald DW (2009a) Effect of field margins on moths depends on species mobility: field based evidence for landscape-scale conservation. Agric Ecosyst Environ 129:302-309

Merckx T, Feber RE, Riordan P, Townsend MC, Bourn NAD, Parsons MS, Macdonald DW (2009b) Optimising the biodiversity gain from agri-environment schemes. Agric Ecosyst Environ 130:177-182

Merckx T, Feber RE, Parsons MS, Bourn NAD, Townsend MC, Riordan P, Macdonald DW (2010a) Habitat preference and mobility of Polia bombycina: are non-tailored agri-environment schemes any good for a rare and localised species? J Insect Conserv 14:499-510

Merckx T, Feber R, Mclaughlan C, Bourn N, Parsons M, Townsend M, Riordan P, Macdonald D (2010b) Shelter benefits less mobile 
moth species: the field-scale effect of hedgerow trees Agriculture. Ecosyst Environ 138:147-151

Natural England (2013a) Environmental Stewardship. http://www. naturalengland.gov.uk/ourwork/farming/funding/es/default.aspx. Accessed 02 July 14

Natural England (2013b) Higher Level stewardship, 4th edn. Natural England, Sheffield

Ouin A, Burel F (2002) Influence of herbaceous elements on butterfly diversity in hedgerow agricultural landscapes. Agric Ecosyst Environ 93:45-53

Passek JE (1988) 30. Influence of wind and windbreaks on local dispersal of insects. Agric Ecosyst Environ 22-23:539-554

Slade EM, Merckx T, Riutta T, Bebber DP, Redhead D, Riordan P, Macdonald DW (2013) Life-history traits and landscape characteristics predict macro-moth responses to forest fragmentation. Ecology 94:1519-1530

van Langevelde F, Ettema JA, Donners M, Wallis De Vries MF, Groenendijk D (2011) Effect of spectral composition of artificial light on the attraction of moths. Biol Conserv 144:2274-2281

Waring P, Townsend P, Lewington R (2009) Field guide to the moths of Great Britain and Ireland, 2nd edn. British Wildlife Publishing, Dorset

White RH, Stevenson RD, Bennett RR, Cutler DE (1994) Wavelength discrimination and the role of ultraviolet vision in the feeding behavior of hawkmoths. Biotropica 26:427-435

Yela JL, Holyoak M (1997) Effects of moonlight and meteorological factors on light and bait trap catches of noctuid moths (Lepidoptera: Noctuidae). Environ Entomol 26:1283-1290 